05;06

\title{
Безвакуумный метод получения кубического карбида титана в плазме низковольтного дугового разряда постоянного тока
}

\author{
(C) А.Я. Пак \\ Национальный исследовательский Томский политехнический университет, Томск, Россия \\ E-mail: ayapak@tpu.ru
}

Поступило в Редакцию 29 августа 2018 г.

\begin{abstract}
Представлены результаты исследований по получению кубического карбида титана в плазме дугового разряда постоянного тока, инициированного в открытой воздушной среде. Особенностью изложенного метода является его реализация без применения газовых или жидких защитных сред, предотвращающих окисление продуктов и исходных реагентов кислородом воздуха. По данным рентгеновской дифрактометрии в составе порошкового продукта идентифицированы графит $\mathrm{gC}$, гексагональный титан $\alpha$-Ті, кубический карбид титана ТіС. Частицы ТіС представлены объектами с правильной характерной огранкой и размерами от единиц до десятков микрометров.
\end{abstract}

DOI: 10.21883/PJTF.2019.01.47146.17506

Карбид титана является широко известным сверхтвердым материалом с относительно невысокой плотностью, который также характеризуется отличной износостойкостью, высокой температурой плавления, стойкостью к коррозии, хорошей электропроводностью, каталитической активностью [1-3]. В последние годы интерес к методам получения и свойствам карбида титана возрастает, в том числе ввиду его возможного применения для создания накопителей электрической энергии сверхвысокой удельной емкости $\left(\sim 100-900 \mathrm{~F} / \mathrm{cm}^{3}\right)$ [4,5]. Для получения карбида титана используются различные техники: карботермическое восстановление, осаждение парогазовой смеси, генерация плазмы, лазерная абляция и т.д. $[1,2,6]$. Одним из современных методов получения порошкового карбида титана является электродуговой метод [7]. В настоящей работе изложены результаты экспериментальных исследований, свидетельствующие о возможности получения порошкового карбида титана в плазме дугового разряда постоянного тока, инициированного в разрядном промежутке между графитовыми электродами, находящимися в открытой воздушной среде. Подобный метод активно используется для получения углеродных ультрадисперсных материалов [8], карбида бора [9]. При этом сообщений о применении подобной техники для синтеза карбида титана не обнаружено.

Экспериментальные исследования проводились на электродуговом плазмохимическом реакторе постоянного тока. Основу установки составляют графитовые анод в виде цилиндрического стержня и катод в форме тигля. На дно тигля помещается смесь титана и графита в соотношении $1: 1$ at.\% в количестве $0.60 \pm 0.05 \mathrm{~g}$. Анод и смесь исходных реагентов на дне тигля образуют разрядный промежуток, в котором инициируется дуговой разряд. В серии экспериментов изменялась энергия разряда путем управления длительностью его горения (до $20 \mathrm{~s}$ ) при силе постоянного тока $\sim 170$ А. Рабочие ток $i(t)$ и напряжение на разряде $u(t)$ в каждом экспе- рименте регистрировались при помощи цифрового осциллографа Rigol DS1052E. Энергия $w$ дугового разряда определялась путем интегрирования кривой мощности по времени; мощность $p(t)$ вычислялась перемножением напряжения $u(t)$ и тока $i(t)$.

Полученный порошковый материал анализировался методами рентгеновской дифрактометрии (Shimadzu XRD7000s, CuK $K_{\alpha}$-излучение, графитовый монохроматор), растровой электронной микроскопии (Tescan Vega 3 SBU c энергодисперсионным анализатором Oxford X-Max-50; JEOL JSM 7500F).

На рис. 1 представлены типичные рентгеновские дифрактограммы смеси исходных реагентов и продукта синтеза. Согласно качественному анализу, в составе продукта можно выделить следующие кристаллические фазы: графит gС, гексагональный титан $\alpha$-Ті и кубическая модификация карбида титана ТiC. Фазы $\mathrm{gC}$ и $\alpha$-Ті в составе продукта можно отнести к непрореагировавшим в процессе синтеза компонентам исходной смеси. Также явно заметно раздвоение основного гра-

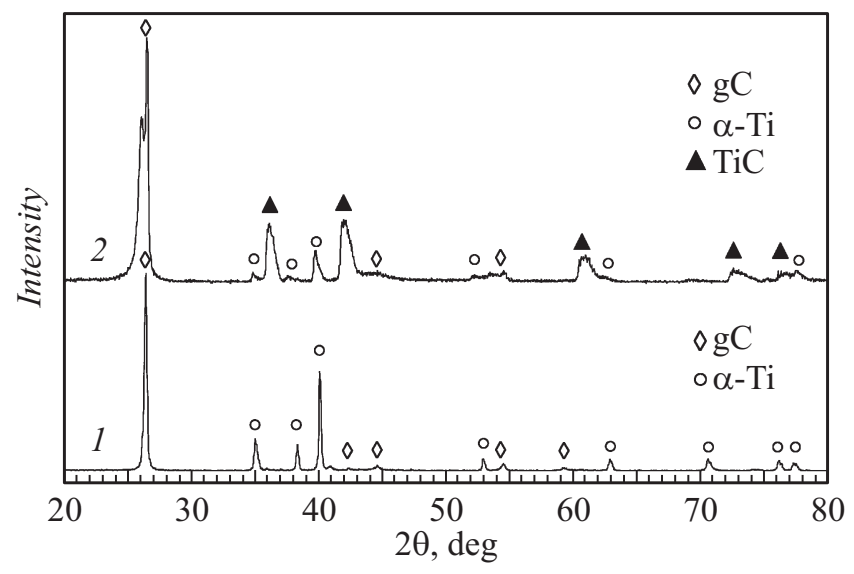

Рис. 1. Типичные рентгеновские дифрактограммы исходной смеси (1) и продукта синтеза (2). 


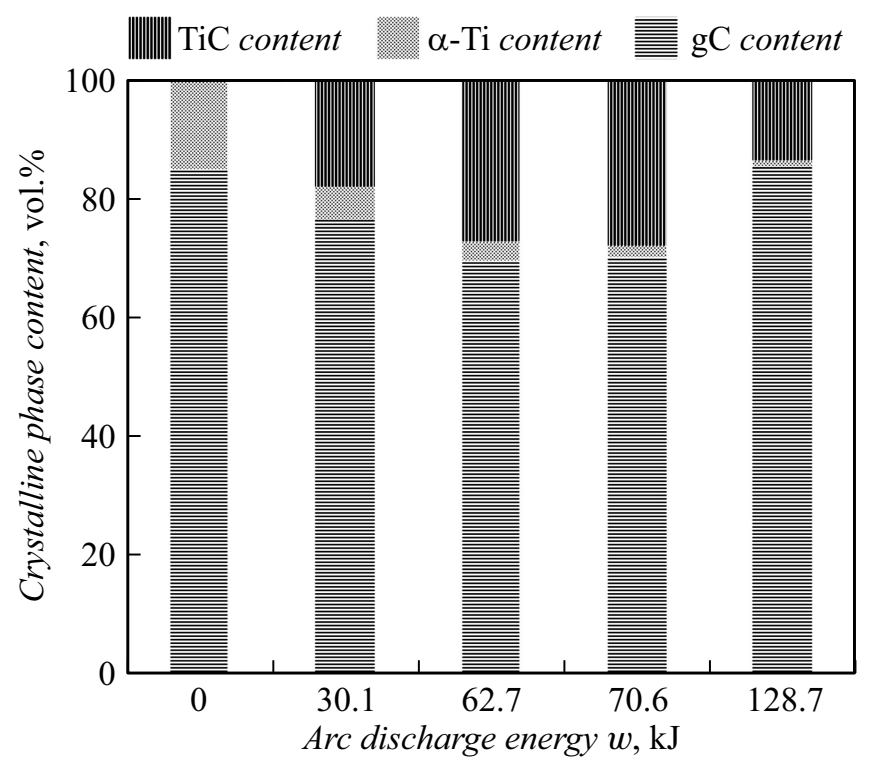

Рис. 2. Зависимость содержания кристаллических фаз в составе продукта синтеза от энергии дугового разряда.

фитового максимума, свидетельствующего о появлении в продукте графитоподобной углеродной фазы, отличной от исходного графита. Этот факт представляется естественным ввиду эффекта электрической эрозии и попадания материала электродов в продукт [10], что подтверждается увеличением массы продукта относительно массы смеси исходных реагентов на величину до $\sim 0.5 \mathrm{~g}$. Полученная фаза кубического ТiC характеризуется параметром элементарной ячейки $a=4.3208 \AA$ при отклонении $\Delta=0.0041 \AA$ (по данным семи экспериментов). Положения дифракционных максимумов и величина $a=4.3208 \AA$ наиболее соответствуют в пределах базы данных PDF4+ эталону N 04-003-6209 кубического $\operatorname{TiC}(a=4.3200 \AA)$. В соответствии с представлениями о зависимости параметра элементарной ячейки кубического $\mathrm{TiC}\left(\mathrm{TiC}_{1-x}\right)$ от соотношения его компонентов [11] доля углерода в обсуждаемом карбиде титана составляет порядка 41 at.\%. При этом форма дифракционных максимумов типичных дифрактограмм, а именно неявный характер положения вершин, позволяет предполагать наличие в продукте помимо обозначенной выше также фаз карбида титана с долей углерода от $\sim 34$ до $\sim 44$ at.\% [11]. В целом результаты качественного рентгенофазового анализа согласуются с известными сведениями о диаграмме состояний системы Ti-C [12]. Следует отметить, что не обнаружены дифракционные максимумы, отвечающие различным фазам оксида титана.

По данным количественного рентгенофазового анализа продуктов серии экспериментов построена зависимость фазового состава полученных материалов от энергии дугового разряда $w$ (рис. 2). Видно, что доля $\alpha$-Ті уменьшается с ростом $w$ на всем исследуемом интервале от 0 (т. е. без воздействия разряда) до $128.7 \mathrm{~kJ}$.
Доля кубического $\mathrm{TiC}$ возрастает (до $\sim 28 \%$ ) одновременно со снижением доли $\alpha$-Ті на интервале от 0 до $70.6 \mathrm{~kJ}$; при уровне энергии выше $70.6 \mathrm{~kJ}$ доля $\mathrm{TiC}$ снижается. При этом доля графита уменьшается на интервале от 0 до $62.7 \mathrm{~kJ}$ и возрастает при большем уровне $w$. Такой характер зависимости можно объяснить следующим образом: при горении дугового разряда исходная смесь $\mathrm{gC}$ и $\alpha$-Ті расходуется, образуется ТiC, при этом процесс сопровождается электроэрозией анода с переносом массы углерода на катод (в продукт).

По данным растровой электронной микроскопии во всех полученных продуктах синтеза можно выделить три типа объектов (рис. 3). Объекты первого типа это скопления частиц с неразличимой по имеющимся снимкам морфологией и наименьшей плотностью (судя по изображениям в режиме фазового контраста). По всей видимости, объекты первого типа - это графит, который в рамках настоящей работы не представляет особого интереса. Объекты второго типа - это частицы неправильной формы с размерами несколько десятков микрометров; объекты второго типа характеризуются наибольшей плотностью среди рассматриваемых частиц, а также округлой формой, которая предположительно может быть сформирована в результате плавления титана в ходе работы установки. Энергодисперсионные спектры, полученные от скоплений частиц, где доминируют объекты второго типа, показали в рассматриваемых областях повышенное относительно других
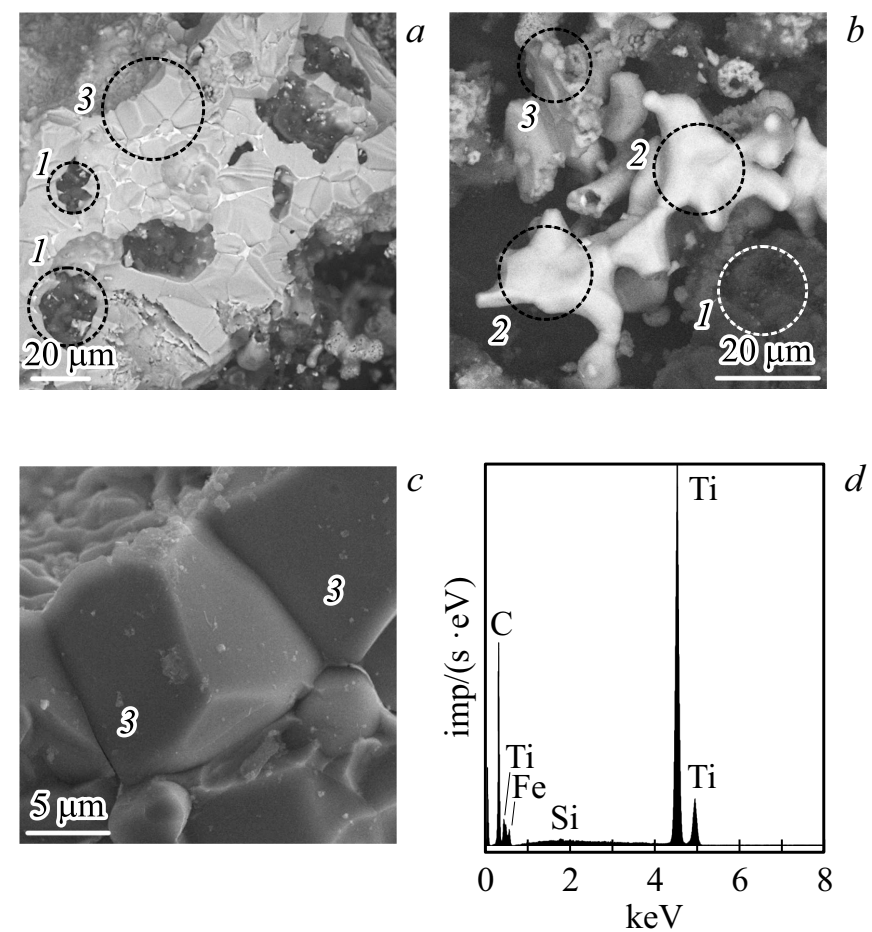

Рис. 3. Данные растровой электронной микроскопии. $a-c-$ снимки объектов первого $(\mathrm{gC})$, второго $(\alpha-\mathrm{Ti})$ и третьего (TiC) типов, цифры $1-3$ соответствуют типам объектов; $d-$ типичный энергодисперсионный спектр. 
содержание титана. Таким образом, объекты второго типа можно с высокой вероятностью отнести к фазе $\alpha$-Ті. Объекты третьего типа - это частицы с размерами от единиц до десятков микрометров с естественной правильной огранкой. По данным энергодисперсионного анализа объекты третьего типа состоят из углерода и титана. При усреднении результатов 24 измерений получено следующее содержание химических элементов в областях, где доминируют объекты третьего типа: содержание титана - 50.5 wt.\%, углерода - 45.5 wt.\%, прочих элементов (железа, кремния, алюминия и других загрязнений в виде распространенных элементов) 4.0 wt.\%. Объекты третьего типа идентифицированы как карбид титана ТіС. При этом широкое распределение частиц по размерам представляется нормальным для электродугового метода синтеза [13].

Полный химический анализ полученных материалов, проведенный на различных участках проб, свидетельствует о том, что усредненное содержание углерода в типичном образце составляет $48.7 \mathrm{wt} \%$, титана 48.1 wt.\%. Суммарное содержание прочих химических элементов составляет на различных участках от $\sim 1$ до 5-7 wt.\%, в единичных случаях - до 10-13 wt.\%. Основными примесными элементами (загрязнениями) являются $\mathrm{O}, \mathrm{Al}, \mathrm{Si}, \mathrm{P}, \mathrm{K}, \mathrm{Ca}, \mathrm{Fe}, \mathrm{Ni}$. Металлические загрязнения могут попадать в продукт ввиду их наличия в контактных элементах, подводящих электропитание к электродам. Следует отметить, что содержание кислорода свыше $\sim 2-3$ wt.\% характерно лишь для трех проведенных анализов (из нескольких десятков). Таким образом, в продукте возможно нахождение небольшого содержания оксидных и/или оксикарбидных фаз (и/или адсорбированного кислорода), однако на этом этапе исследований не удалось выделить и идентифицировать кислородсодержащую составляющую.

По совокупности представленных выше данных следует считать возможным получение порошкового ТіС в плазме низковольтного дугового разряда, инициированного в воздушной атмосфере. Изложенный метод основан на известных данных о генерации газовой атмосферы СО при горении дугового разряда постоянного тока в воздушной среде. В настоящее время такой подход является одним из перспективных путей разработки новых безвакуумных электродуговых методов получения углеродных материалов $[8,10]$, а именно углеродных нанотрубок. К недостаткам разрабатываемого метода следует отнести невысокое содержание искомой фазы ТiC, значительное загрязнение продукта электроэрозионным графитом и остатками смеси исходных реагентов, широкое распределение частиц по размерам. Основной новизной и достоинством метода можно считать его реализацию без применения вакуумного и газового оборудования в составе экспериментальной установки.

Автор благодарит М.А. Рудмина за проведение съемки на растровом электронном микроскопе.

\section{Список литературы}

[1] Rasaki S.A., Zhang B., Anbalgam K., Thomas T., Yang M. // Progr. Solid State Chem. 2018. V. 50. P. 1-15. https://doi.org/10.1016/j.progsolidstchem.2018.05.001

[2] Cho D., Park J.H., Jeong Y., Joo Y.L. // Ceram. Int. 2015. V. 41. P. 10974-10979. http://dx.doi.org/10.1016/j.ceramint.2015.05.041

[3] Dong Q., Huang M., Guo C., Yu G., Wu M. // Int. J. Hydrogen Energy. 2017. V. 42. P. 3206-3214. http://dx.doi.org/10.1016/j.jhydene.2016.09.217

[4] Ghidiu M., Lukatskaya M.R., Zhao M.-Q., Gogotsi Y., Barsoum M.W. // Nature. 2014. V. 516. P. 78-89. DOI: $10.1038 /$ nature 13970

[5] Lin S.-Y., Zhang X. // J. Power Sources. 2015. V. 294. P. 354 359. http://dx.doi.org/10.1016/j.jpowsour.2015.06.082

[6] De Bonis A., Santagata A., Galasso A., Laurita A., Teghil R. // J. Colloid Interface Sci. 2017. V. 489. P. 76-84. http://dx.doi.org/10.1016/j.jcis.2016.08.078

[7] Yu J., Yu H., Gao J., Zhou L., Ding A., Gao X., Huang H., Gao S., Shah A., Dong X., Quan X. // J. Alloys Compd. 2017. V. 693. P. $500-509$. http://dx.doi.org/10.1016/j.jallcom.2016.09.232

[8] Su Y., Wei H., Li T., Geng H., Zhang Y. // Mater. Res. Bull. 2014. V. 50. P. 23-25. http://dx.doi.org/10.1016/j.materresbull.2013.10.013

[9] Пак А.Я., Мамонтов Г.Я. // Письма в ЖТФ. 2018. Т. 44. B. 14. C. 26-33. DOI: 10.21883/PJTF.2019.01.47146.17506

[10] Arora N., Sharma N.N. // Diamond Related Mater. 2014. V. 50. P. $135-150$. https://doi.org/10.1016/j.diamond.2014.10.001

[11] Predel B. // Landolt-Börnstein. Numerical data and functional relationships in science and technology. Berlin-Heidelberg: Springer, 1992. Group IV. V. 5b. P. 1-5. https://doi.org/10.1007/10040476_671

[12] Frisk K. // Comput. Coupling Phase Diagrams Thermochem. 2003. V. 27. P. 367-373. DOI: $10.1016 /$ j.calphad.2004.01.004

[13] Ремпель А.А. // Успехи химии. 2007. Т. 76. В. 5. С. 474-500. DOI: https://doi.org/10.1070/RC2007v076n05ABEH003674 